\title{
Análisis de las medidas de asistencia a víctimas de trata de personas en Colombia en perspectiva de derechos humanos
}

\author{
Johana Reyes Jaimes" \\ Jakeline Vargas Parra"* \\ Juan C. Aceros"***
}

\author{
Recibido: 9 de diciembre de 2016 • Aprobado: 1 de noviembre de 2017 \\ https://doi.org/10.22395/ojum.v17n33a4
}

\section{RESUMEN}

La trata de personas se configura como una grave vulneración a los derechos humanos, lo cual obliga a los Estados a garantizar la asistencia y protección integral fundamentada en la reparación de quienes han sufrido dichas vulneraciones. A partir de la metodología de revisión documental, este artículo analiza la normativa aplicable a la asistencia y protección a víctimas de trata de personas en Colombia a la luz de los principios y directrices recomendados sobre derechos humanos y trata de personas. Los principios corresponden a la no detención o enjuiciamiento por delitos relacionados con la condición de víctima de trata; protección y apoyo a víctimas; asistencia jurídica, protección y permisos de residencia temporales; derechos y necesidades de los niños; y regreso voluntario y en condiciones de seguridad. Los principales resultados evidencian que se han hecho importantes esfuerzos para incluir estas perspectivas de derechos humanos en la normativa colombiana. Sin embargo, solo se ha incluido como una directriz teórica en la mayoría de los documentos de trata de personas del país, sin traducirse en acciones concretas que favorezcan la recuperación de las víctimas.

Palabras clave: trata de personas; asistencia y protección a víctimas; enfoque basado en derechos humanos; políticas públicas.

Este artículo se deriva del proyecto de investigación en curso Sentipensar la trata: Experiencia de investigación participativa sobre la asistencia y protección a víctimas de trata de personas en Santander (2016-2017), adelantado por los grupos de investigación en Ciencias Sociales, Humanidades y Educación (CISNHE), de la Universidad Manuela Beltrán seccional Bucaramanga y el Grupo de Investigación en Políticas Públicas del Instituto de Estudios Políticos de la Universidad Autónoma de Bucaramanga.

" Abogada de la Universidad Autónoma de Bucaramanga (Colombia). Magíster en Gestión y Políticas Públicas de la Universidad Industrial de Santander (Colombia). Actualmente docente investigadora de la Universidad Manuela Beltrán seccional Bucaramanga (Colombia); miembro del grupo de investigación en Ciencias Sociales, Humanidades y Educación (CISNHE) de la misma universidad. Los temas de investigación se circunscriben al ámbito de los derechos humanos, la trata de personas y las políticas públicas. Correo electrónico: johana.reyes@docentes.umb.edu.co. Orcid 0000-0001-7303-2044

... Trabajadora Social de la Universidad Industrial de Santander (Colombia). Administradora Pública de la Escuela Superior de Administración Pública (Colombia). Magíster en Políticas Públicas y Gerenciamiento del Desarrollo, de la Universidad Nacional de San Martín (Argentina). Actualmente docente e investigadora del Instituto de Estudios Políticos adscrito a la Facultad de Estudios Jurídicos y Políticos de la Universidad Autónoma de Bucaramanga (Colombia). Presidenta del Observatorio Latinoamericano sobre trata y tráfico de personas ObservaLAtrata. Directora del grupo de investigación Instituciones Políticas y Opinión Pública y Líder de la línea de investigación sobre Trata de Personas. Integrante del grupo Ciencia Política y líder de la línea de investigación en Políticas Públicas. Correo electrónico: jvargas557@unab.edu.co. Orcid 0000-0002-2351-558X

"... Psicólogo de la Universidad Pontificia Bolivariana de Bucaramanga (Colombia). Doctor en Psicología Social de la Universidad Autónoma de Barcelona (España). Actualmente es parte del grupo de investigación en Ciencias Sociales, Humanidades y Educación (CISNHE) de la Universidad Manuela Beltrán (Colombia). También es profesor de la Escuela de Trabajo Social de la Universidad Industrial de Santander (Colombia). Sus temas de investigación se circunscriben al ámbito de la psicología social discursiva y los estudios sociales de la ciencia y la tecnología. Correo electrónico: juan.aceros@docentes. umb.edu.co. Orcid 0000-0003-2707-5419 


\title{
Analysis of Measures to Assist Victims of Human Trafficking in Colombia from a Human Rights perspective
}

\begin{abstract}
Human trafficking is a serious violation of human rights, which obliges Governments to guarantee comprehensive assistance and protection based on reparation for those who have suffered such violations. Based on the document review methodology, this paper analyses the regulations applicable to the assistance and protection of victims of human trafficking in Colombia in the light of the recommended principles and guidelines on human rights and human trafficking. The principles relate to the non-arrest or prosecution of offences related to the status of victims of trafficking; protection and support for victims; legal assistance, protection and temporary residence permits; children's rights and needs; and safe and voluntary return. The main results show that significant efforts have been made to include these human rights perspectives in Colombian law. However, it has only been included as a theoretical guideline in most of the country's human trafficking documents, without being translated into concrete actions that favor the recovery of victims.
\end{abstract}

Keywords: human trafficking; victim assistance and protection; human rights-based approach; public policies.

\section{Análise das medidas de assistência a vítimas de tráfico de pessoas na Colômbia, na perspectiva dos direitos humanos}

\section{RESUMO}

O tráfico de pessoas configura-se como uma grave violação dos direitos humanos, o que obriga os Estados a garantirem assistência e proteção integral fundamentada na recuperação daqueles que sofreram tais violações. A partir da metodologia de revisão documental, este artigo analisa a legislação aplicável à assistência e proteção das vítimas de tráfico de pessoas na Colômbia à luz dos princípios e diretrizes recomendados sobre direitos humanos e tráfico de pessoas. Os princípios correspondem à não detenção ou julgamento por delitos relacionados com a condição da vítima de tráfico; proteção e apoio a vítimas; assistência jurídica, proteção e autorizações temporárias de residência; direitos e necessidades das crianças e retorno voluntário e em condições de segurança. Os principais resultados evidenciam que importantes esforços foram realizados para incluir essas perspectivas dos direitos humanos na legislação colombiana. No entanto, foram incluídas apenas como uma diretriz teórica na maioria dos documentos de tráfico de pessoas do país, sem traduzir-se em ações concretas que favoreçam a recuperação das vítimas.

Palavras-chave: Assistência e proteção a vítimas; enfoque baseado nos direitos humanos; políticas públicas; tráfico de pessoas. 


\section{INTRODUCCIÓN}

Actualmente existe consenso en que para combatir la trata de personas de manera eficaz, se requiere abarcar todas las modalidades y fases del fenómeno desde una perspectiva integral de derechos humanos ${ }^{1}$ y exigir el reconocimiento de la responsabilidad de los gobiernos en la protección de los mismos (Oacnudh, 2010). El enfoque basado en derechos humanos (EBDH) implica también que las políticas públicas estén fundadas en la reivindicación de los derechos de las víctimas y en los distintos procesos de su desarrollo (Jiménez, 2007).

A pesar de dicho consenso en torno al enfoque de derechos humanos, las políticas y marcos normativos nacionales e internacionales no siempre reflejan estas disposiciones. Por el contrario, prima aún el enfoque de criminalización del delito, dado que para un Estado abarcar integralmente el enfoque equivaldría también a reconocer su responsabilidad legal por casos de trata de personas (Bravo, 2015; Londoño Toro, Varón Mejía, E Luna de

Se considera que la trata de personas vulnera la prohibición de discriminar por motivos de raza, color, sexo, idioma, religión, opinión política o de otra índole; el derecho a la vida; la libertad y la seguridad; a no ser sometido a esclavitud, servidumbre, trabajo forzoso o trabajo en condiciones de servidumbre por deudas; a no ser sometido a torturas y/o tratos o penas crueles, inhumanos o degradantes; a no sufrir violencia de género; la libertad de asociación; libertad de circulación; el derecho al disfrute del más alto nivel posible de salud física y mental; el derecho a condiciones de trabajo equitativas y satisfactorias; a un nivel de vida adecuado; a la seguridad social; y el derecho del niño a una protección especial (Oficina del Alto Comisionado de Naciones Unidas, 2014).
Aliaga, 2012; Becerra Barbosa, Cortés Nieto, López Rodriguéz, \& Quintero, 2011). Al presente, se desconoce el real alcance y utilización del EBDH dentro del marco normativo colombiano aplicable a la asistencia a víctimas. Por tal razón, el propósito del documento es examinar la implementación del enfoque de derechos humanos en la normativa colombiana sobre trata de personas, específicamente en el eje de protección y asistencia a víctimas que ha sido uno de los temas críticos en el país dentro del abordaje del delito (Montenegro, 2015; Alianza Global contra la Trata de Mujeres (GAATW), 2015; Flamtermesky, 2014).

El análisis de las políticas implementadas y la normativa existente en asistencia a víctimas de trata de personas requiere preguntarse por la congruencia de estos documentos con los principios que definen el enfoque de derechos humanos. Esto ha de hacerse tanto al nivel nacional, como al regional, dada la descentralización de la lucha contra la trata que se ha promovido en Colombia a partir de la Ley 985 del 2005. Al nivel regional este artículo examina el caso del departamento de Santander, una región a la que se ha reconocido en repetidas ocasiones como un modelo en la lucha contra la trata de personas.

En las siguientes páginas se avanza, a través del método documental, en el análisis de 15 normas al nivel nacional, y 3 al nivel departamental. Estas normativas se examinaron a la luz de un conjunto de indicadores basados en las disposiciones de los Principios y Directrices Recomen- 
dados sobre Derechos Humanos y Trata de Personas (Oacnudh, 2010), que constituye el principal instrumento de abordaje del delito con observancia del enfoque de derechos humanos. En esta dirección se pretende dar respuesta a la siguiente pregunta: ¿La normativa en materia de asistencia y protección a las víctimas de trata de personas en Colombia se ajusta a los principios y directrices recomendados sobre derechos humanos y trata de personas?

Los principales resultados evidencian una implementación parcial del enfoque basado en derechos humanos, específicamente desde lo teórico. Sin embargo, estos enfoques teóricos y de principios no han logrado materializarse en prácticas concretas de atención a víctimas de trata de personas en Colombia y Santander. Esto es reflejo de que aún persiste una visión general de la asistencia a las víctimas de trata de personas y, por tanto, en muchos casos no se otorga una atención especializada, desconociendo las particularidades y la gravedad del delito.

El documento se ha estructurado en cuatro secciones: la primera corresponde a una conceptualización general sobre el EBDH y la importancia de su implementación en las políticas públicas; la segunda sección enuncia las directrices y principios que refieren la existencia de un EBDH en la lucha contra la trata de personas; posteriormente se presenta un recuento de la normativa sobre trata y la metodología del trabajo; seguidamente se señalan los resultados de la revisión de la normativa nacional y de la departamental, desvelando los principales contenidos con relación a cada indicador de derechos humanos. Finalmente, se discuten los principales hallazgos desde la perspectiva de la descentralización y desde el cumplimiento de los lineamientos de derechos humanos.

\section{ENFOQUE DE DERECHOS HUMANOS Y POLITICAS PÚBLICAS}

El enfoque basado en derechos humanos (EBDH) se fundamenta sobre la idea de una ética universal de la que se desprende un conjunto de derechos aplicables a cualquier ser humano (Jiménez, 20107). Este enfoque ha tenido un desarrollo académico relativamente reciente en el ámbito de las políticas públicas. Sin embargo, ha venido ganando terreno en los últimos años (Jiménez, 2007; Guendel, 2002). En la actualidad se está aplicando en las diferentes fases de la política pública², además de figurar en el objeto de muchas de ellas. Su origen está relacionado principalmente con las disposiciones de Naciones Unidas, así como de organizaciones de cooperación internacional que divulgaron y promocionaron la implementación de medidas de derechos humanos en el desarrollo de proyectos sociales (Oficina del Alto Comisionado de las Naciones Unidas, 2006).

\footnotetext{
Al hablar de fases de las políticas públicas se hace referencia al ciclo de Jones (1970) que incluye las fases de identificación del problema, formulación de soluciones, toma de decisiones, implementación y evaluación.
} 
La implementación del EBDH en la legislación y en las políticas públicas puede justificarse desde distintas perspectivas. Desde el punto de vista de los fines que persigue, puede decirse que su principal objetivo es materializar o concretar los postulados tradicionales de los derechos humanos. Esto significa que el EBDH busca orientar todas las acciones del Estado en el bienestar de la persona. Así se puede decir que el EBDH está en concordancia con la teoría del derecho útil o derecho regulativo que define el derecho como medio para la obtención de determinados fines, valores o intereses (Jiménez, 2007).

De otro lado, el EBDH puede interpretarse como parte de la obligatoriedad de los Estados de ser garantes de los derechos humanos. La adaptación del EBDH a las políticas públicas fortalece el eje de acción gubernamental en dicha dirección. Por ende, en concordancia con la idea de las políticas públicas como el "conjunto de sucesivas iniciativas, decisiones y acciones del régimen político frente a situaciones socialmente problemáticas y que buscan la resolución de las mismas o llevarlas a niveles manejables" (Vargas, 1999, citado por Roth, 2010, p. 21), se puede decir que si se implementa el enfoque, los Estados dan respuesta a un problema que en esencia corresponde a una vulneración de los derechos humanos. Por tanto, los Estados, actuando desde el enfoque, estarían dando resolución o mitigando dicha situación garantizando el ejercicio pleno de los derechos de las víctimas, en el caso específico de las políticas de protección y asistencia en la trata de personas.
Finalmente, también se puede entender el enfoque de derechos humanos desde su aporte al desarrollo integral de las sociedades. El EBDH enfatiza en la necesidad de implementar estrategias en pro de la transformación de las relaciones de poder imperantes, corrigiendo las desigualdades, las prácticas discriminatorias y las injusticias (Institut de Drets Humans, 2014). En este sentido, el enfoque se entiende como un camino para la realización del ser humano y el logro de un mayor desarrollo social.

Cabe señalar que, más allá del discurso de los derechos humanos y de la teorización de los gobiernos en las políticas públicas, se debe garantizar el diseño de políticas que desarrollen acciones constantes en la dirección de incluir cada principio "apuntando a ser de alguna manera el espíritu de lo que da sentido a la política como ligazón con la actuación del ciudadano" (Barco, 2016, pág. 59).

\subsection{La asistencia a víctimas de trata de personas y el enfoque de derechos humanos}

Para los propósitos de este trabajo, es necesario identificar las estrategias y medidas que orientan la implementación del EBDH en las políticas públicas sobre asistencia y protección a las víctimas de trata de personas. Al respecto, cabe resaltar que la mayoría de estudios jurídicos sobre asistencia en el delito se fundamentan en el examen del Protocolo de Palermo y de las características del delito (Mateus, Varón Mejía, Londoño Toro, Luna de Aliaga, E Vanegas Moyano, 2009; Londoño Toro, Varón Mejía, \& Luna de Aliaga, 2012; y 
Bravo, 2015), dejando de lado otras disposiciones Normativas, Como El Código Penal, el Código de Procedimiento Penal, las disposiciones sobre la cuenta especial, la trata de personas en el marco del conflicto armado, entre otras. Sin embargo, en este trabajo, dichos mandatos legales se han tenido en cuenta debido a que pueden ser aplicables al tema, independientemente de no tener especificidad sobre trata de personas. Así, se espera ofrecer un panorama más amplio del estado de la asistencia y protección a víctimas de trata del país.

De manera general, la inclusión del EBDH en la trata de personas implica labores como la protección y promoción de los derechos humanos, la comprensión de las formas de vulneración en todo el ciclo de la trata de personas, la corrección de prácticas discriminatorias y la búsqueda de la justicia y la reparación para las víctimas (Oficina del Alto Comisionado de Naciones Unidas, 2014). Esta introducción del enfoque de derechos en el abordaje del delito se sustenta sobre dos presupuestos. En primer lugar, se entiende que el EBDH está íntimamente ligado a la comprensión contemporánea de la trata de personas. En la revisión teórica realizada por Becerra y otros (2011), este enfoque aparece como uno de los más relevantes. En efecto, la trata de personas se considera como una vulneración a los derechos a la libertad, la no discriminación, la vida, la seguridad, la dignidad, entre otros. En segundo lugar, la trata de personas se entiende como relacionada con el EBDH en el derecho internacional. Este último ampara todos los derechos de las víctimas de trata, sin importar la condición de nacionales o no nacionales (Oficina del Alto Comisionado de Naciones Unidas, 2014).

A pesar dela evidente relación entrela trata de personas y los derechos humanos, en la actualidad no todos los instrumentos estatales para combatirla se enmarcan dentro del EBDH. Junto con el enfoque de derechos encontramos otras perspectivas que rigen el accionar institucional y que coexisten con el EBDH. Entre ellos se encuentran los enfoques de lucha contra la delincuencia, la justicia penal, las migraciones, la explotación sexual y el trabajo (Oacnudh, 2010). De acuerdo con autores como Bravo (2015), el enfoque imperante en la legislación internacional es el de criminalización o de lucha contra la delincuencia. El mismo aborda el delito de trata de personas como "una infracción al orden público internacional y a la dignidad de los seres humanos, la cual, por su extrema gravedad, supone que los autores del delito deban ser castigados por el derecho penal" (Bravo, 2015, pág. 41). Dada la complejidad del fenómeno, se hace necesario que la trata de personas se aborde desde diversas perspectivas o enfoques. Sin embargo, debe primar siempre el enfoque de derechos humanos en cualquier tipo de mecanismo de acción contra el delito, esto, principalmente, en razón a la vulneración de derechos humanos que se configura por la comisión del delito.

Para materializar los postulados de derechos humanos la Oficina del Alto Comisionado para los Derechos Humanos (Oacnudh, 2010) ha diseñado una serie de 
principios rectores que buscan la orientación de toda actividad estatal encaminada a combatir el fenómeno. Los principios y directrices recomendados sobre derechos humanos y trata de personas buscan servir de guía práctica para los países en la implementación de acciones y facilitar la integración del EBDH en las leyes, políticas e intervenciones nacionales, regionales e internacionales contra la trata de personas (Oacnudh, 2010).

Es importante recalcar el carácter no obligatorio de estos principios, ya que constituyen recomendaciones no vinculantes para los Estados. A pesar de ello, algunas de las recomendaciones están contenidas en protocolos y convenios internacionales que las dotan de obligatoriedad para los países. Colombia no ha ratificado los convenios $^{3}$ o acuerdos que harían obligatoria y vinculante esta disposición. A su vez, se hace evidente que el Protocolo para Prevenir, Reprimir y Sancionar la trata de personas tampoco incluye expresamente esta disposición.

A continuación, se señalan los principios específicos en asistencia a víctimas, formulados por el Alto Comisionado de las Naciones Unidas (2010).

i. Principio de no detención o enjuiciamiento por delitos relacionados con la condición de víctima de la trata

En la práctica, es frecuente que las víctimas de trata de personas sean

3 Por ejemplo, el Convenio Europeo sobre la trata de seres humanos del 2005, que contiene normas específicas sobre la no imposición de sanciones a víctimas obligadas a cometer actividades ilícitas. detenidas o judicializadas en algunos países donde la prostitución o mendicidad son prohibidas. Lo mismo suele ocurrir en casos en los que las víctimas portan documentos falsos o están indocumentadas, razones por las cuales terminan siendo detenidas. El primer principio se opone a tales situaciones.

ii. Protección y apoyo a las víctimas

El segundo principio constituye uno de los pilares fundamentales en la atención e implica para los Estados garantizar la protección y la no repetición de hechos vulneratorios contra las víctimas. De igual forma se establece la responsabilidad del Estado en la debida diligencia, para brindar la seguridad y la protección necesarias a las víctimas. A la luz de este principio, la asistencia debe ser reconocida como un derecho de toda víctima, sin dar lugar a negociaciones ni demás trabas por parte de los gobiernos.

iii. Asistencia jurídica, protección y permisos de residencia temporales

La inclusión de este principio se sitúa en el proceso penal o civil que se ejecute contra los tratantes. Mediante este se propende por una participación activa de la víctima en los procesos de investigación y judicialización. Para tal efecto, debe estar plenamente informada, y su libertad y su seguridad deben estar garantizadas. Además, en relación con el principio de no enjuiciamiento, la concesión de 
permisos de residencia temporales busca evitar detenciones o penalizaciones a las víctimas por la condición, en algunos casos, de migrantes irregulares.

iv. Derechos y necesidades especiales de los niños

Históricamente los niños, niñas y adolescentes han sido considerados como sujetos en condiciones de inferioridad con respecto a los demás integrantes de la sociedad. Las diferentes concepciones sociales han llevado a que estos hayan sido determinados como sujetos sin autodeterminación ni autonomía. Sin embargo, estas concepciones han venido cambiando y los diferentes organismos procuran una protección especial a los menores, quienes son merecedores de un amparo específico. De esta protección especial no se excluye el delito de trata de personas. Por el contrario, en la actualidad se reconoce el principio de interés superior del niño y se encuentra ampliamente difundido por la doctrina internacional sobre trata de personas.

v. Regreso voluntario y en condiciones de seguridad

Este principio propende por evitar las deportaciones forzosas de las víctimas y los traslados que pongan en riesgo la seguridad. Asimismo, busca garantizar la seguridad en la repatriación y la voluntariedad de las víctimas para efectuar dichos traslados.

\section{EL DELITO DE TRATA DE PERSONAS EN EL MARCO NORMATIVO COLOMBIANO}

El Protocolo de Palermo (Oficina de las Naciones Unidas contra la Droga y el Delito, 2000) es el instrumento jurídico internacional por excelencia con el que cuenta Colombia para enfrentar la trata de personas. El mismo fue ratificado mediante la Ley 800 del 2003. Posteriormente, la Ley 985 del 2005 incluye el concepto de trata de personas con los parámetros del protocolo y regula las acciones para combatir el fenómeno en el país. En efecto, el Protocolo de Palermo ha establecido una definición de trata de personas que se ha venido trasladando a la normativa de los distintos Estados que lo han ratificado. La misma conjuga tipificaciones de diversos fenómenos considerados antes como delitos distintos, y se estructura a partir de varios elementos: i. Las acciones, o lo que se hace cuando se lleva a cabo la trata; ii. Los medios por los que se realizan las acciones; y ii. La finalidad que se persigue: la "Explotación".

La definición de trata de personas es ampliamente compartida por los Estados que han ratificado el Protocolo de Palermo. Sin embargo, persisten debates sobre la naturaleza del fenómeno. Algunos autores señalan el fenómeno de trata de personas como un delito de lesa humanidad. Sin embargo, para catalogarlo de esta forma "hay que tener en cuenta que deben existir unos parámetros exigidos por los instrumentos del derecho penal internacional, y secundados por la jurisprudencia internacional y colombiana" (Mateus, Varón Mejía, Londoño Toro, 
Luna de Aliaga, E Vanegas Moyano, 2009). Por este motivo, la legislación colombiana define la trata de personas como un delito común.

Al haber ratificado el Protocolo de Palermo, diversos protocolos y convenios internacionales sobre trata de personas, Colombia se obliga y compromete a cumplir las disposiciones acordadas. Estas disposiciones incluyen la protección y asistencia a víctimas que, en la normativa nacional, se encuentran referenciadas como el "conjunto de medidas, mecanismos y proyectos a cargo de las entidades con competencia en el tema, que están encaminadas a garantizar la prestación de servicios de protección y asistencia a las víctimas de la trata de personas, así como a sus familiares hasta el primer grado de consanguinidad, primero civil y al cónyuge o compañero (a) permanente" (Ley 1069 del 2014, artículo 2 numeral 5). A pesar de existir la definición anterior es evidente que su lectura no aporta mayores aclaraciones sobre el tema, pues define en los mismos términos el concepto de "protección y asistencia".

A pesar de la importancia dada a la protección y asistencia a víctimas en la política de lucha contra la trata en Colombia, esta última suele enmarcarse predominantemente en el enfoque de criminalización. Por tanto, en su mayoría, los contenidos del Protocolo implican un discurso relativamente pobre sobre los derechos humanos. Esto se evidencia en el uso del lenguaje dentro de dicho instrumento. Por ejemplo, mientras se hacen obligatorias y exigibles las mate- rias relacionadas con la aplicación de la ley, en lo atinente a la asistencia a víctimas no se hace ninguna exigencia, sino que se hacen recomendaciones que los Estados no necesariamente tienen que seguir o aplicar (Global Rights, 2005). Solo a través de documentos posteriores o complementarios se enfatiza en la necesidad de incluir dicha perspectiva ${ }^{4}$. Así pues, es posible anticipar que el EBDH no se encuentre ampliamente desarrollado en la política nacional ni en la regional colombiana. Los resultados del análisis realizado así lo indican. Para desarrollar esta idea, se procede a presentar la metodología.

\section{METODOLOGÍA}

El presente estudio hizo uso del método documental (Botero, 2000). El proceso de revisión permitió la identificación de 15 documentos normativos al nivel nacional, y 3, al nivel departamental. Las figuras 2 y 3 presentan el listado de los referentes normativos encontrados. Cabe mencionar que para este estudio se ha tomado no solo la normativa exclusiva de trata de personas, sino que se han abordado otros marcos legislativos, como el Código Penal colombiano y el Código de Procedimiento Penal, entre otros. Dichos documentos sirven subsidiariamente en la atención a las víctimas en caso de vacíos legislativos del decreto de asistencia a víctimas de trata de personas, en concordancia con las reglas de interpretación del derecho.

\footnotetext{
4 Por ejemplo, los Principios y directrices recomendados sobre derechos humanos (2002) y la Guía Anotada de los mismos (2010), sobre los cuales versa el presente artículo.
} 
De igual forma cabe aclarar que algunos de los documentos a la fecha son inexequibles, pero su enunciación es necesaria para conocer el proceso por el cual ha atravesado el país en materia de trata de personas.

Tabla 1. Marco normativo colombiano sobre asistencia a víctimas de trata de personas

\begin{tabular}{|c|c|}
\hline Norma & Contenido \\
\hline $\begin{array}{l}\text { Decreto } 1974 \text { de } \\
1996\end{array}$ & $\begin{array}{l}\text { Crea el Comité Interinstitucional para la Lucha contra el Tráfico de Mujeres, Niñas } \\
\text { y Niños. } \\
\text { Primer precedente del actual comité interinstitucional sobre trata de Personas. }\end{array}$ \\
\hline $\begin{array}{l}\text { Decreto } 1456 \text { de } \\
1997\end{array}$ & $\begin{array}{l}\text { Modifica decreto anterior sobre el Comité Interinstitucional para la Lucha contra el } \\
\text { Tráfico de Mujeres, Niñas y Niños. } \\
\text { Disminuyó la periodicidad de las reuniones del comité que antes se circunscribían a } \\
\text { una por bimestre. El nuevo texto señala una reunión cada cuatro meses. }\end{array}$ \\
\hline Ley 599 de 2000 & $\begin{array}{l}\text { Código Penal colombiano. Delito de trata de personas, artículo } 188^{a} \text { delitos contra la } \\
\text { autonomía. Adicionado por el artículo 2, Ley } 747 \text { de 2002, modificado por el artículo } \\
\text { 3, Ley } 985 \text { de } 2005 \text {. }\end{array}$ \\
\hline Ley 800 de 2003 & Aprueba el Protocolo de Palermo. \\
\hline Ley 985 de 2005 & $\begin{array}{l}\text { Adopta medidas contra la trata de personas y normas para la atención y protección } \\
\text { de las víctimas. Principal marco de acción contra la trata al nivel nacional, descen- } \\
\text { traliza la política pública. }\end{array}$ \\
\hline Ley 906 de 2004 & Código de Procedimiento Penal Colombiano. \\
\hline $\begin{array}{l}\text { Decreto } 4319 \text { de } \\
2006^{*}\end{array}$ & $\begin{array}{l}\text { Establece la organización y el funcionamiento de la cuenta especial creada para la } \\
\text { Lucha contra la Trata de Personas. Posteriormente estos artículos son compilados } \\
\text { en el Decreto Único Reglamentario } 1066 \text { de 2015, por medio del cual se expide el } \\
\text { Decreto Único Reglamentario del Sector Administrativo del Interior. }\end{array}$ \\
\hline $\begin{array}{l}\text { Ley } 1098 \text { del } \\
2006\end{array}$ & $\begin{array}{l}\text { Código de Infancia y Adolescencia, incluye disposiciones sobre los procedimientos } \\
\text { especiales para cuando los niños, las niñas o los adolescentes son víctimas de de- } \\
\text { litos (Título II, capítulo único). }\end{array}$ \\
\hline $\begin{array}{l}\text { Decreto } 4786 \text { de } \\
2008\end{array}$ & $\begin{array}{l}\text { Adopta la política pública contra la trata de personas "Estrategia Nacional Integral } \\
\text { contra la Trata de Personas 2007-2012". }\end{array}$ \\
\hline $\begin{array}{l}\text { Ley } 1448 \text { de } \\
2011\end{array}$ & $\begin{array}{l}\text { Medidas de atención, asistencia y reparación integral a las víctimas del conflicto } \\
\text { armado interno y se dictan otras disposiciones. }\end{array}$ \\
\hline $\begin{array}{l}\text { Ley } 1719 \text { de } \\
2014\end{array}$ & $\begin{array}{l}\text { Modifica algunos artículos de las leyes } 599 \text { de } 2000 \text { y } 906 \text { de } 2004 \text { y se adoptan me- } \\
\text { didas para garantizar el acceso a la justicia de las víctimas de violencia sexual en el } \\
\text { conflicto armado. Crea el tipo penal de trata de personas en persona protegida con } \\
\text { fines de explotación sexual. }\end{array}$ \\
\hline Ley 10692014 & $\begin{array}{l}\text { Reglamenta la asistencia a víctimas de trata de personas conforme a las disposicio- } \\
\text { nes de la Ley } 985 \text { del } 2005 .\end{array}$ \\
\hline $\begin{array}{l}\text { Decreto Único } \\
\text { Reglamentario } \\
1066 \text { de } 2015\end{array}$ & $\begin{array}{l}\text { Decreto Único Reglamentario del Sector Administrativo del Interior. } \\
\text { Recoge y compila las disposiciones del Decreto de Asistencia a Víctimas y de la } \\
\text { Cuenta Especial. }\end{array}$ \\
\hline $\begin{array}{l}\text { Decreto } 1036 \text { de } \\
2016\end{array}$ & Aprueba la estrategia nacional integral sobre trata de personas 2016-2018. \\
\hline
\end{tabular}

Decretos compilados por el Decreto Único Reglamentario 1066 del 2015. Para efectos de diferenciar dichos instrumentos en esta investigación se denominarán por el número de decreto originario antes de la compilación.

Fuente: elaboración propia con base en revisión documental 
Tabla 2. Marco normativo de Santander sobre asistencia a víctimas de trata de personas

\begin{tabular}{|l|l|}
\hline \multicolumn{1}{|c|}{ Norma } & \multicolumn{1}{c|}{ Contenido } \\
\hline Decreto 0250 del 2008 & Reglamenta el Comité Departamental de trata de personas de Santander \\
\hline \multirow{3}{*}{ Ordenanza 076 del 2013 } & $\begin{array}{l}\text { Implementa la política pública departamental sobre trata de personas. } \\
\text { Adopta los ejes de acción nacionales y modifica algunas de las funciones } \\
\text { del comité de trata de personas establecidas en el Decreto 0250 del 2008 }\end{array}$ \\
\hline \multirow{5}{*}{ Ordenanza 012 del 2016 } & $\begin{array}{l}\text { Plan de desarrollo departamental "Santander Nos Une" 2016-2019. Inclu- } \\
\text { ye el fenómeno de la trata de personas dentro del eje "Temas de Desarro- } \\
\text { llo de Derechos Humanos (DDHH) y Derecho Internacional Humanitario } \\
\text { (DHI); Inclusión Social, Reintegración y Reconciliación". Además, señala } \\
\text { como única acción "Implementar una política pública departamental de } \\
\text { lucha contra la trata de personas" (pág. 325). }\end{array}$ \\
\hline
\end{tabular}

Fuente: elaboración propia con base en revisión documental

Una vez identificados los documentos a examinar, los mismos se han analizado mediante la aplicación de un conjunto de indicadores basados en los Principios y Directrices Recomendados sobre Derechos Humanos y Trata de Personas de la Oficina del Alto Comisionado para los Derechos Humanos de las Naciones Unidas (2002), así como la guía comentada de dichos principios, también del Alto Comisionado, y la Declaración Universal de Derechos Humanos (2010) y el Convenio del Consejo de Europa sobre la lucha contra la trata de seres humanos (2005). La figura 3 presenta los indicadores utilizados.

\section{RESULTADOS}

\section{Principio de no detención o enjuiciamiento por delitos relacionados con la condición de víctima}

Este principio es, quizá, uno de los más complejos, ya que involucra la inclusión de normativas especiales en los códigos penales y la existencia de procedimientos que permitan la rápida identificación de las víctimas de trata de personas (Indicador 1.1.). En este sentido, el análisis evidencia que en el ordenamiento jurídico colombiano no existe un procedimiento orientado a la correcta y ágil identificación de las víctimas. Sin embargo, se pueden interpretar algunas disposiciones como relacionadas con este asunto. Por ejemplo, el artículo 4 del Decreto 1974 de 1996 proponía como función del Comité Interinstitucional de Trata de Personas: coordinar el diseño e implementación de un sistema de información y procesamiento de datos de las redes criminales y de "las potenciales víctimas". Sin embargo, esta propuesta no ha llegado a materializarse. Más recientemente, el Decreto 1036 del 2016 ha establecido la creación del Sistema Nacional de Información sobre la Trata de Personas y de un Observatorio del Delito de Trata de Personas. No obstante, estas medidas propenden por la sistematización de información general, relativa a las causas, características y dimensiones de la trata interna y externa en Colombia, y no tienen que ver directamente con los procesos de 
Tabla 3. Indicadores de enfoque de derechos humanos por cada principio

\begin{tabular}{|c|c|c|}
\hline \multicolumn{3}{|r|}{ Indicadores de derechos humanos para la asistencia a víctimas de trata de personas } \\
\hline N. ${ }^{\circ}$ & Principio & Indicadores \\
\hline \multirow{7}{*}{ i. } & \multirow{7}{*}{$\begin{array}{l}\text { No detención } \\
\text { o enjuicia- } \\
\text { miento por } \\
\text { delitos rela- } \\
\text { cionados con } \\
\text { la condición } \\
\text { de víctima de } \\
\text { la trata }\end{array}$} & $\begin{array}{l}\text { 1.1. La existencia de dispositivos que permitan la correcta y ágil identificación de las víctimas } \\
\text { (procedimientos, medidas, e indicadores para la identificación). }\end{array}$ \\
\hline & & $\begin{array}{l}\text { 1.2. La inclusión en las normativas nacionales de disposiciones relacionadas con la no } \\
\text { detención o enjuiciamiento por delitos conexos con la situación de víctimas. }\end{array}$ \\
\hline & & $\begin{array}{l}\text { 1.3. Independencia en el marco normativo entre la prestación de asistencia a víctimas y la } \\
\text { identificación, aprehensión y enjuiciamiento del victimario. }\end{array}$ \\
\hline & & $\begin{array}{l}\text { 1.4. Presencia en el marco normativo de disposiciones sobre la prestación de asistencia a } \\
\text { víctimas independientemente de la relación familiar entre víctima y perpetrador. }\end{array}$ \\
\hline & & $\begin{array}{l}\text { 1.5. Disposiciones que evidencien la libertad de movilidad de las víctimas una vez han sido } \\
\text { identificadas (Por ejemplo, la no obligatoriedad de permanecer en los programas de } \\
\text { asistencia). }\end{array}$ \\
\hline & & $\begin{array}{l}\text { 1.6. Designación de tutores para acompañamiento a menores de edad, durante todo el proceso } \\
\text { y hasta que se aplique una solución final. }\end{array}$ \\
\hline & & 1.7. Disposiciones sobre apoyo consular para víctimas detenidas. \\
\hline \multirow{6}{*}{ ii. } & \multirow{6}{*}{$\begin{array}{l}\text { Protección } y \\
\text { apoyo a las } \\
\text { víctimas }\end{array}$} & $\begin{array}{l}\text { 2.1. Disposiciones de protección dirigidas a nacionales y no nacionales (la normativa contempla } \\
\text { protección tanto para nacionales como extranjeros). }\end{array}$ \\
\hline & & 2.2. Disposiciones sobre apoyo a las víctimas independientemente de su cooperación. \\
\hline & & $\begin{array}{l}\text { 2.3. Medidas como el acceso efectivo a una vivienda adecuada y segura y una asistencia } \\
\text { psicológica, médica y material. }\end{array}$ \\
\hline & & $\begin{array}{l}\text { 2.4. Existencia de períodos de reflexión para las víctimas o presuntas víctimas (para la toma } \\
\text { de decisiones, la aceptación de la asistencia, entre otras). }\end{array}$ \\
\hline & & $\begin{array}{l}\text { 2.5. Promoción de alianzas con cooperación internacional y organizaciones para atención a } \\
\text { víctimas. }\end{array}$ \\
\hline & & $\begin{array}{l}\text { 2.6. Presencia de medidas de atención con diferenciación de género* (entiéndase medidas, } \\
\text { como, por ejemplo, de hospedaje, asistencia en salud sexual y reproductiva, programas } \\
\text { especiales que evidencien efectivamente un uso del enfoque en la práctica). }\end{array}$ \\
\hline \multirow{5}{*}{ iii. } & \multirow{5}{*}{$\begin{array}{l}\text { Asistencia } \\
\text { jurídica, } \\
\text { protección y } \\
\text { permisos de } \\
\text { residencia } \\
\text { temporales }\end{array}$} & 3.1. Se brinda información sobre los procedimientos judiciales y administrativos pertinentes. \\
\hline & & $\begin{array}{l}\text { 3.2. Se ofrece asesoramiento e información en lo relativo a los derechos que les reconoce la } \\
\text { ley en un idioma que puedan comprender las víctimas. }\end{array}$ \\
\hline & & 3.3. Se determina de un lugar seguro en el país de destino de las víctimas. \\
\hline & & $\begin{array}{l}\text { 3.4. Se ofrecen procedimientos que garanticen la protección de la identidad en el curso de } \\
\text { los procesos judiciales. }\end{array}$ \\
\hline & & $\begin{array}{l}\text { 3.5. Se otorgan concesiones de permisos de residencia temporal durante los procedimientos } \\
\text { judiciales. }\end{array}$ \\
\hline \multirow{3}{*}{ iv. } & \multirow{3}{*}{$\begin{array}{l}\text { Regreso vo- } \\
\text { luntario y en } \\
\text { condiciones de } \\
\text { seguridad }\end{array}$} & 5.1. Mecanismos de seguridad para la repatriación. \\
\hline & & 5.2. Procedimientos para evaluaciones individuales del riesgo. \\
\hline & & 5.3. Disposiciones que promuevan el regreso voluntario de las víctimas a sus países de origen. \\
\hline
\end{tabular}

Fuente: elaboración propia con base en revisión documental 
identificación de víctimas. Más claro es el aporte de la Ley 1448 de 2011 y de la Ley 1719 de 2014 (aplicables a las víctimas de trata de personas dentro del conflicto armado colombiano). En estas leyes se les asigna a los jueces el papel de reconocer e identificar a las víctimas directas e indirectas, e individualizar los daños y perjuicios (ver, por ejemplo, el artículo 52 de la Ley 1719 de 2014). En el ámbito departamental, no se encontró ninguna medida relacionada con la identificación de las víctimas, ni la existencia de lineamientos normativos para la misma.

Dentro de los indicadores de este principio, se debe destacar también que en las normativas revisadas tanto nacionales como departamentales, no existen disposiciones relacionadas con la no detención o enjuiciamiento por delitos conexos con la situación de víctimas de trata de personas (Indicador 1.2.). En cambio, sí existen en el Código de Procedimiento Penal colombiano y al nivel departamental normativas expresas que señalan que la condición de víctima se tiene con independencia de que se identifique, aprehen$\mathrm{da}$, enjuicie o condene al autor del injusto (Indicador 1.3) e independientemente de la existencia de una relación familiar con este (Indicador 1.4.). En este sentido, pueden consultarse el artículo 132 del Código de Procedimiento Penal colombiano y el artículo 2, numeral 1 del Decreto 1069 de 2014. En los casos de víctimas de trata de personas en el marco del conflicto armado, la normativa también comprende expresamente mandatos relacionados. Por ejemplo, el acceso a los programas de protección a víctimas y testigos de la
Fiscalía General de la Nación "no podrá condicionarse a la eficacia o utilidad de la participación de la víctima, para la recolección de elementos probatorios o para la identificación del autor del hecho" (artículo 22, N.․ 10, Ley 1719 de 2014). Al nivel departamental, el Plan de Desarrollo 2016-2019 recalca: "la atención a las víctimas de trata de personas se debe ofrecer tan pronto se conozca el caso, y no se debe esperar a la emisión de la sentencia del mismo" (Plan de Desarrollo Departamental, pág. 131).

Así, pues, en principio, las víctimas tienen garantizada la asistencia con independencia del enjuiciamiento del victimario. Sin embargo, hasta hace poco esto no era cierto para el caso de la atención mediata. El Decreto 1069 del 2014 sobre asistencia a víctimas de trata de personas condicionaba este tipo de asistencia a la imposición de la respectiva denuncia. Esto tenía repercusiones tanto al nivel nacional, como al territorial, de tal manera que determinaba la forma como se asiste a las víctimas en los departamentos, distritos y municipios, sobre los que recae un buen número de competencias en protección y asistencia a víctimas. Esta disposición es inaplicable en la actualidad debido a su declaración de inexequibilidad, la cual fue comunicada el 31 de agosto del 2016.

Ninguno de los documentos normativos revisados establece, ni al nivel nacional ni al territorial, la libertad de movilidad de las víctimas una vez identificadas (Indicador 1.5). Sin embargo, tal libertad podría interpretarse desde la posibilidad de renunciar a los programas de asistencia en cualquier 
momento (artículo 39 Ley 10692014 recogido por el Decreto 1066 del 2015).

Con respecto al principio de no detención y enjuiciamiento, un aspecto importante a tener en cuenta se refiere a la designación de tutores para asistir todos los procesos de los menores de edad víctimas (Indicador 1.6). Se trata de un aspecto que la normativa examinada no contempla. No obstante, los menores se encuentran amparados por diversos mecanismos de protección que garantizan en mayor medida la reparación y reintegración. Así, por ejemplo, el artículo 193 del Código de Infancia y Adolescencia establece la citación a los representantes del menor y de un defensor de familia, en los procesos en los que los niños y las niñas son víctimas de delitos. El Decreto 1069 del 2014 (Compilado por el Decreto 1066 del 2015) también señala la participación de los defensores de familia, comisarios de familia o inspectores de familia sin perjuicio de que el niño, niña o adolescente cuente con representante y de ser necesario se contempla el traslado del menor al Instituto Colombiano de Bienestar Familiar (ICBF) (Artículo 8). Se debe tener en cuenta que estas disposiciones del Código de Infancia y Adolescencia se aplican a los menores, víctimas de cualquier delito, ya que en Colombia no existen lineamientos para atención específica en trata de personas donde las víctimas son niños, niñas y adolescentes 5 .

5 Se sabe que UNODC y el ICBF, se encuentran en la elaboración de dichas directrices específicas. Comunicación personal Rocio Urón. (septiembre, 2016) asesora de coordinación de la territorial de Naciones Unidas contra la Droga y el Delito en Bucaramanga.
Finalmente, dentro de este principio se consideran las disposiciones sobre apoyo consular para las víctimas (Indicador 1.7). Frente a esto, normativas como la Ley 985 de 2005 instan a que en "cada consulado de Colombia en el exterior se ofrezca la información y las medidas temporales para garantizar la seguridad de la víctima, salvaguardar su dignidad e integridad personal y apoyarla en las gestiones que deba adelantar ante las autoridades del país extranjero. (...) Los consulados propenderán, además, por incentivar el análisis del tema y sensibilizar a los medios de comunicación y a las autoridades extranjeras frente a la situación de sus víctimas" (artículo 7 numeral 3). También la Estrategia Nacional 2007-2012 contemplaba dentro de sus objetivos "impulsar gestiones consulares que garanticen la seguridad de las víctimas, salvaguardar su dignidad e integridad personal" (Decreto 4786 de 2008, artículo 1, eje de Protección y Asistencia a Víctimas).

\subsection{Protección y apoyo a las víctimas}

Este principio comprende múltiples estrategias orientadas a la satisfacción de las necesidades de las víctimas y a la prestación de servicios médicos y psicológicos, entre otras actividades. Con respecto al indicador 2.1., sobre disposiciones de protección dirigidas a nacionales y no nacionales, debe afirmarse que, de acuerdo con la Constitución Política y al Código Penal colombiano, las medidas de atención se aplican dentro del territorio colombiano, tanto para nacionales como para extranjeros. Esto también es aplicable a las garantías y derechos que debe brindar el 
Estado (artículo 4 Constitución Política; artículo 14 Código Penal). De manera más específica, la Ley 985 del 2005 contempla dentro de su principal objetivo "adoptar medidas de prevención, protección y asistencia necesarias... tanto las residentes o trasladadas en el territorio nacional, como los colombianos en el exterior" (artículo 1). El término "trasladado en el territorio nacional" sería de aplicación a aquellos extranjeros que se encuentren en el país y sean identificados como víctimas. El Decreto de Asistencia a Víctimas, por su parte, contiene disposiciones específicas para que los no nacionales que hayan sido trasladados a Colombia sean repatriados al país de origen. Estas medidas consisten en adelantar las gestiones correspondientes con el país de origen para su traslado, así como para prestar la atención y asistencia a que hubiere lugar (artículo 9). Si la víctima desea quedarse en Colombia, las autoridades solo tienen la competencia de otorgarle la información sobre los procedimientos para residir regularmente. Por su parte, este mismo decreto señala que se gestionarán los documentos de identificación de las víctimas tanto nacionales como extranjeras para su repatriación o el ejercicio de sus derechos (artículo 11). Igualmente, el decreto en el artículo 33 establece que los niños, las niñas y los adolescentes extranjeros que sean víctimas en Colombia serán atendidos de acuerdo con los procedimientos especiales que contempla el ICBF. Asimismo, se gestiona inmediatamente la repatriación del menor a su lugar de origen. Al nivel departamental no se presentan medidas con diferenciación de nacionales y extranjeros.
En lo concerniente al apoyo a las víctimas con independencia de su cooperación en el proceso (Indicador 2.2.), el análisis no revela su aplicación en el marco normativo nacional ni en el departamental. Por el contrario, como ya hemos dicho, la asistencia mediata había estado supeditada a que la víctima denunciara el delito ante las autoridades competentes (parágrafo 1 artículo 7 de la Ley 985 del 2005 y Decreto 1069 del 2014 articulo 2 parágrafo del N. ${ }^{\circ}$ 8 , parágrafo que la Corte Constitucional declaró inexequible en la sentencia C-470 del 2016). En este orden de ideas, se hacía confusa la anterior disposición, por dos aspectos principales. El primero, porque la trata de personas es un delito de oficio, es decir, no necesita denuncia para que se inicie su investigación, actuando las autoridades de oficio. El segundo, que los funcionarios públicos tienen el deber de informar de los hechos delictivos de los que tengan conocimiento. Ante cualquier caso de trata el funcionario debería oficiar a la fiscalía para iniciar la respectiva investigación. Por estas razones consideró la Corte Constitucional que el decreto de asistencia a víctimas se contrariaba con las disposiciones del Código Penal colombiano.

El apoyo a las víctimas con independencia de su cooperación en el proceso tampoco es claro en el caso de los niños, niñas y adolescentes. La norma determina que los menores entrarán a los programas del ICBF, pero no se determina hasta qué punto llegará la atención y si es necesaria la denuncia de los menores. Una disposición relacionada se puede interpretar como la contenida en el Código de Procedimiento 
Penal, que establece que solo para el caso del derecho a recibir información se la dará "A quien demuestre sumariamente su calidad de víctima, la policía judicial y la Fiscalía General de la Nación le suministrarán información" (artículo 136 Código de Procedimiento Penal). La expresión "sumariamente" hace referencia a la prueba que no ha sido controvertida y esto se puede aplicar al proceso de atención en el entendido de que la víctima no necesita presentar denuncia para recibir atención.

Finalmente, las víctimas de trata de personas en el marco del conflicto armado se encuentran más ampliamente amparadas en atención a que se les prestará protección antes de la denuncia del hecho. Así, el artículo 22 de la Ley 1719 establece que "Ningún funcionario podrá coaccionar a la víctima a rendir declaración sobre los hechos antes de contar con una medida de protección idónea y que garantice unas condiciones de seguridad y confianza para formular la denuncia". Cabe recalcar que lo anterior solo es aplicable a las víctimas de trata en el marco del conflicto armado. Quienes no ostenten esta condición se rigen por la normativa específica en trata (Decreto de asistencia a víctimas) que, como se ha visto, había presentado vacíos al respecto. En el plan de desarrollo departamental se presentan medidas específicas, como se mencionó en párrafos anteriores.

Las medidas de acceso a vivienda adecuada, segura y asistencia médica, psicológica y material (indicador 2.3) se encuentran contempladas especialmente en el Código de Procedimiento Penal. Este, en su ar- tículo 134, formula que las víctimas podrán solicitar al juez por conducto de un fiscal las medidas indispensables para su atención y protección. Además, el Decreto de Asistencia a Víctimas establece que se prestará dentro de la asistencia inmediata la valoración del estado de salud física y mental para determinar y realizar las acciones de atención en salud con el fin de contrarrestar las afectaciones sufridas (artículo 2, N. 11 Decreto 1069 del 2014). Sin embargo, debe señalar que, en cuanto al acceso a vivienda, la normativa no contempla ninguna disposición específica, ni tampoco se señalan los procedimientos para acceder a ella. Ahora bien, la asistencia médica y psicológica mediata "Consiste en la prestación de servicios en salud física y mental a las víctimas de la trata de personas de acuerdo con la normativa vigente que regula el Sistema General de Seguridad Social en Salud -SGSSS-" (artículo 2, N.. 12 Decreto 1069 del 2014). Así pues, no se contempla un procedimiento especial para las víctimas, únicamente se limita a realizar la "afiliación" al sistema de salud. En este aspecto, el alcance de la norma es mínimo y, por tanto, la protección, insuficiente.

El marco normativo colombiano no presenta ninguna disposición en la que se señalen tiempos de reflexión para las víctimas (Indicador 2.4.), ya que no existen períodos para toma de decisiones, espacios de asimilación, ni ningún término para esto. Por su parte, el indicador 2.5., sobre la promoción de alianzas con cooperación internacional, ha sido contemplado en todo el desarrollo de la normativa sobre trata, como el Decreto 
1974 de 1996, la Estrategia Nacional Integral 2007 y la 2016 y el Decreto 1069 del 2014, los cuales promueven alianzas con organismos de cooperación internacional y organizaciones para la atención a víctimas.

Finalmente, el enfoque de género (Indicador 2.6.) se ve incluido en el Código de Infancia y Adolescencia, en la Estrategia Nacional Integral contra la Trata de Personas 2007-2012, en la Ley 1719 de 2014 y en la Ley 1448 de 2011 para víctimas del conflicto armado, y en el Decreto 1036 de 2016. Asimismo, en el ámbito regional se contempla Decreto 0250 del 2008 que reglamenta el Comité Departamental de Trata de Personas, y la Ordenanza 076 del 2013 que comprende la implementación de política pública sobre trata de personas en Santander. Todos los documentos plantean al enfoque de género dentro de sus principios rectores o ejes de acción. Sin embargo, en los contenidos de los mismos no se evidencian acciones en las que se refleje este enfoque, como lo serían disposición de alojamientos con enfoque de género o diferenciado. La enunciación se hace de manera general, pero sin contener medidas específicas que determinen y garanticen una verdadera atención con enfoque de género.

\subsection{Asistencia jurídica, protección y permisos de residencia temporales}

Nuestro análisis evidencia que este principio se encuentra garantizado de manera más amplia dentro del marco normativo nacional. Como se ha señalado al respecto de los principios anteriores, el Código de Procedimiento Penal contiene disposiciones expresas sobre el derecho de las víctimas a recibir información de los procesos judiciales y los derechos que las asisten (Indicador 3.1.). Igualmente recalca la necesidad de que la información se brinde con ayuda de traductores de ser necesario (Indicador 3.2.) (ver, artículos 11, 135 y 136). De igual manera, la Ley 800 de 2003 que aprueba el Protocolo de Palermo señala el deber para cada Estado de proporcionar la información pertinente a las víctimas.

En cuanto a la determinación de un lugar seguro en el país de destino de las víctimas (Indicador 3.3.), se considera que ciertas medidas del Código Penal abordan dicha situación. Por ejemplo, el artículo 50 contempla "La privación del derecho a residir o de acudir a determinados lugares impide al penado volver al lugar en que haya cometido la infracción, o a aquel en que resida la víctima o su familia, si fueren distintos". También, el Código de Procedimiento Penal contiene disposiciones que pretenden dar seguridad a las víctimas (Indicador 3.3). Los artículos 133 y 137 señalan la seguridad entre las garantías de las víctimas. Esta la pueden solicitar por intermedio del fiscal: "Las víctimas podrán solicitar al fiscal en cualquier momento de la actuación medidas de protección frente a probables hostigamientos, amenazas o atentados en su contra o de sus familiares" (artículo 137). A su vez, la Ley 985 del 2005 contempla en el artículo 8 la vinculación a los programas de protección de la Fiscalía, durante todo el proceso penal o mientras subsisten los factores de riesgo que lo justifiquen. Res- 
pecto al papel de la Fiscalía es necesario recalcar su importancia como protector de las víctimas; en este sentido una de sus funciones consiste en velar por la protección de estas, así como de los testigos y peritos que la Fiscalía pretenda presentar (artículo 114 C. P. P.).

En referencia a la existencia de procedimientos que garanticen la protección de la identidad en el curso de los procesos judiciales (Indicador 3.4.), el análisis indica que el Estado colombiano contempla la realización de los interrogatorios de las víctimas con base en los principios de respeto de su situación personal, derechos y dignidad (artículo 137 Código de Procedimiento Penal). En este sentido, se podría interpretar que la anterior disposición se configura como un mecanismo de protección por lo menos en la realización de los interrogatorios. A su vez, se establece que los procedimientos de la Fiscalía sobre protección a víctimas y testigos buscan garantizar la seguridad de las víctimas y de quienes comparezcan en el proceso.

Finalmente, el indicador 3.5 corresponde a la inclusión en la normativa de permisos de residencia temporales durante los procedimientos judiciales para las víctimas. La revisión documental indica que no existe una disposición sobre el particular. Sin embargo, el Decreto 1069 del 2014, en los artículos 8 y 9, contiene disposiciones sobre repatriación mediante las que se busca brindar ayuda a las víctimas. Concretamente la normativa señala cuestiones sobre todo relacionadas con las funciones del Ministerio de Relaciones Exteriores y los consulados de brindar la información pertinente sobre la permanencia en forma regular en el país.

\subsection{Los derechos y necesidades de los niños}

Este es el principio más ampliamente amparado y contenido por la normativa nacional. Lo anterior se debe en parte a la amplia protección internacional que se ha venido dando en torno al principio del interés superior del niño. Como tal, se hacen más exigibles las garantías relacionadas con los niños, niñas y adolescentes. El indicador 4.4. sobre la presunción de la edad se encuentra amparado en el Código de Infancia y Adolescencia: "Cuando exista duda en relación con la edad del adolescente y mientras la autoridad pericial competente lo define, se presume que es menor de 18 años. En todo caso se presumirá la edad inferior" (artículo 149). Con relación a la presunción de víctimas y procedimientos especiales para la identificación de niños, niñas y adolescentes víctimas (Indicador 4.5.), se tiene que los dispositivos del Código de Infancia y Adolescencia plantean que las autoridades competentes tienen la obligación de verificar el estado de cumplimento de cada uno de los derechos de los niños, niñas y adolescentes. Puede interpretarse que lo anterior configura un mecanismo de identificación de posibles irregularidades que conducirían a la identificación de víctimas (artículo 52).

El indicador de no enjuiciamiento de los menores por ningún delito relacionado con la situación de trata de personas (Indicador 4.6.) no se encuentra presente de manera específica en la legislación. 
Por su parte, el indicador del acceso a la información y respeto a la opinión de los menores (Indicador 4.7.) es considerablemente enunciado en el Código de Infancia y Adolescencia. Ejemplo de lo anterior, son los artículos 34 sobre el derecho a la información, 47 sobre responsabilidades especiales de los medios de comunicación y 193, numerales 7, 8 y 10. Igualmente el indicador 4.8, relacionado con la protección de la identidad del menor, se encuentra amparado por el numeral 8 del artículo 47, en donde se establece que los medios de comunicación deben abstenerse de entrevistar, dar el nombre, divulgar datos que identifiquen o que puedan conducir a la identificación de niños, niñas y adolescentes que hayan sido víctimas, autores o testigos de hechos delictivos (artículo 47, numeral 8 C. I. y A). También el artículo 147, sobre las audiencias que se surtan en el proceso de responsabilidad penal para adolescentes establece que "ante los jueces de control de garantías y ante los jueces de conocimiento, serán cerradas al público si el juez considera que la publicidad del procedimiento expone a un daño psicológico al niño, niña o adolescente". El artículo 194 Contempla que en las audiencias en las que se investiguen y juzguen delitos cuya víctima sea una persona menor de dieciocho (18) años, no se podrá exponer a la víctima frente a su agresor. Para el efecto se utilizará cualquier medio tecnológico y se verificará que el niño, niña o adolescente se encuentre acompañado de un profesional especializado que adecúe el interrogatorio y el contrainterrogatorio a un lenguaje comprensible a su edad. Si el juez lo considera conveniente en ellas solo podrán estar los sujetos procesales, la autoridad judicial, el defensor de familia, los organismos de control y el personal científico que deba apoyar al niño, niña o adolescente.

En el indicador 4.9, sobre la designación de tutores o curadores para los menores se encuentra que el artículo 193 del Código de Infancia y Adolescencia consagra los criterios para el desarrollo del proceso judicial de delitos en los cuales son víctimas los niños, las niñas y los adolescentes. El procedimiento consiste en citar a los padres o representantes legales del menor siempre y cuando no sean los agresores. Sin embargo, se informa a la Defensoría de Familia en los casos en los que el menor no tenga acudiente. Se entiende que la normativa contempla como acompañantes de este proceso al Instituto Colombiano de Bienestar Familiar y la Defensoría de Familia. El Decreto de Asistencia a Víctimas de trata de personas, contempla también dentro de su estructura normativa disposiciones en igual sentido que el Código de Infancia y Adolescencia en cuanto al derecho a la información que debe garantizarse por Defensor de Familia, Comisario de Familia o Inspector de Policía, sin perjuicio de que cuente con representante legal.

En el caso de los niños, las niñas y los adolescentes se privilegiará su interés superior y su condición de sujetos de derechos, y en consecuencia se coordinará el traslado inmediato con la Dirección General del Icbf a través del delegado ante el Comité Interinstitucional para la Lucha Contra la Trata de Personas. 
Finalmente, el indicador 4.10 habla de las medidas para la reunificación familiar en casos de ser beneficiosas para el interés superior del niño. Sobre este se tiene presente que el Defensor de Familia y el Icbf, como garantes de los derechos de los niños deben adoptar las medidas necesarias siempre en pro del interés superior del niño. Se podría entender que dentro de sus funciones está analizar la situación especial de cada menor y determinar en cada caso particular las condiciones sobre las cuales se podría llegar a dar una reunificación familiar, si es lo más conveniente para el menor.

\subsection{Regreso voluntario y en condiciones de seguridad}

El primer indicador de este principio apunta a la existencia de mecanismos de seguridad para la repatriación (Indicador 5.1.). El cumplimiento de dicho indicador se refleja en medidas como las del Código de Procedimiento Penal relacionadas con el deber de la Fiscalía General de la Nación de velar por la protección de víctimas y testigos (artículo 114). Igualmente, la Ley 985 de 2005, en el artículo 8, establece que "El Gobierno coordinará con las entidades pertinentes la organización de un programa de repatriación para las víctimas de trata de personas que se encuentren en el exterior".

El indicador de evaluación individual del riesgo (Indicador 5.2.) está contenido específicamente en la Ley 985 del 2005 sobre los programas de protección de la Fiscalía, los cuales contemplan la realización de evaluaciones de riesgo con el fin de brindar protección integral a testigos y víctimas de la trata de personas. Respecto a las disposiciones que promueven el regreso voluntario de las víctimas (Indicador 5.3), se tiene que estas están supeditadas a los trámites consulares en el caso de las víctimas que se encuentren en países extranjeros.

\section{DISCUSIÓN}

Después de revisar el marco normativo sobre la asistencia a víctimas de trata de personas en Colombia y en el departamento de Santander, se observan algunos puntos sobre los cuales se discutirá. Los mismos son considerados aquí en relación con dos temas: la descentralización de la política pública de trata de personas y la aplicación del Decreto de Asistencia a Víctimas.

La descentralización de la política pública de trata de personas se dio a partir de la expedición de la Ley 985 del 2005. En el entendido de que esta ley buscaba combatir el fenómeno desde los territorios, se esperaría que los departamentos y municipios adaptaran los lineamientos nacionales a las dinámicas territoriales. Pero esto no se ha dado en la práctica, ya que lo que realmente se evidencia es la reproducción de la política nacional, sin atender a las particularidades de cada territorio. Este es, por lo menos, el caso del departamento de Santander. Dado que las unidades administrativas de cada departamento tienen un funcionamiento distinto y procedimientos acordes con las estructuras y presupuestos disponibles, se hace necesaria una política departamental con mayor especificidad, 
concretamente en lo concerniente a la asistencia a víctimas. Al nivel nacional, la política pública establece los lineamientos generales de acción; por su parte, el nivel departamental debería establecer una política que materialice dichos lineamientos nacionales conforme a su capacidad y funcionamiento territorial.

Con respecto a la aplicación del Decreto de Asistencia a Víctimas, el análisis refleja que las disposiciones enunciadas no contribuyen de manera distinta a lo ya contenido en el Código Penal, en el de Procedimiento Penal y en la Ley 985 del 2005. Teniendo en cuenta que los decretos reglamentarios buscan la cumplida ejecución de las leyes (artículo 189, numeral 11, Constitución Política de Colombia), su contenido es de carácter administrativo, y su función es la de "desarrollar y permitir la ejecución de las leyes, o de la regulación, teniendo por lo mismo sus enunciados, fuerza vinculante inferior a la de la ley" (Urrego E Quinche, 2008, pág. 64). Así pues, el Decreto de Asistencia a Víctimas no aporta de manera sustancial a la atención a víctimas en el país ya que se limita a reproducir postulados que ya eran claros en la normativa. Por otro lado, algunas de sus disposiciones contrarían el sistema normativo penal. Esto venía ocu rriendo, por ejemplo, en lo concerniente a la imposición de la denuncia para la prestación de la asistencia mediata. Algunos autores (Urrego \& Quinche, 2008) han planteado que el Estado colombiano con frecuencia transgrede la funcionalidad de los decretos reglamentarios, dado que el "Ejecutivo con el respaldo del Consejo de Estado emite permanentemente decretos que, bajo el pretexto de reglamentar, violan la cláusula general de competencia otorgada al Congreso para hacer las leyes" (Urrego E Quinche, 2008, p. 66). El caso examinado aquí podría configurarse como un ejemplo de lo anterior.

\section{CONCLUSIONES}

Cabe llamar la atención sobre lo que el análisis nos dice en relación con el cumplimiento de las directrices de derechos humanos en la asistencia a víctimas. Al respecto, la aplicación de los indicadores sobre el EBDH sugiere que el enfoque de derechos se ha incluido en el marco normativo nacional y local, pero solo en un grado mínimo. La funcionalidad de la inclusión del EBDH en las políticas públicas es materializar dichos postulados en la acción estatal; las normativas y políticas deben ceñirse a acciones que garanticen efectivamente su cumplimiento. Sin embargo, lo que se observa es que el EBDH solo se ha incluido como una directriz teórica en la mayoría de los documentos de trata de personas del país, sin traducirse en acciones específicas que favorezcan el fortalecimiento de la equidad, la no discriminación, la participación y el empoderamiento (Giménez E Valente, 2010). La mayor parte de los documentos normativos específicos de trata de personas revisados se limitan a exponer en sus preámbulos o introducciones la teorización del EBDH, por lo cual, para garantizar los derechos de las víctimas hay que acudir a otros documentos normativos generales. 
Asimismo, se observa que la normativa de trata carece de medidas específicas (por ejemplo, medidas de alojamiento con un enfoque de género, atención médica y psicológica especializada, entre otras). Esto puede deberse a que, aún al nivel nacional no existen unos lineamientos ni directrices claras sobre el tema. Se debe propender por que las diferentes instituciones desarrollen dichos lineamientos para implementar en su actuar, ya que la normativa se limita solo a enunciar como principio el enfoque de derechos humanos, pero no lo desarrolla. La vaguedad encontrada en la implementación del EBDH también puede deberse a una razón adicional. Con una normativa como la que hemos analizado aquí, el Estado evita comprometerse de manera específica a actividades que requieren de él un mayor esfuerzo y reserva presupuestal.

\section{REFERENCIAS}

Alianza Global contra la Trata de Mujeres (GAATW). (2015). Testimonios de las sobrevivientes de trata de personas: brechas entre las necesidades de atención y los servicios recibidos después del rescate. Argentina, Colombia, México, Ecuador y Perú: Alianza Global contra la Trata de Mujeres (GAATW).

Barco, C. A. (2016). El enfoque basado en derechos ¿Qué es y cómo se aplica a las políticas públicas? Barcelona, España: Universitat Pompeu Fabra. Recuperado de: https://www.upf. edu/dhes-alfa/materiales/res/dhpp_pdf/ DHPP_Manual_v3.51-78.pdf

Becerra Barbosa, G. A., Cortés Nieto, J., López Rodríguez, L. S., y Quintero, R. L. (2011). ¿Cuál es el problema de la trata de personas? Revisión de las posturas teóricas desde las que se aborda. Nova et Vetera, 20 (64), 105-120.
Botero, C. H. (2000). Un modelo para la investigación documental. Medellín: Señal Editora.

Bravo, C. (2015). El problema de la trata de personas: limitaciones de la regulación por el Estado Colombiano. Journal of International Law, 6 (02), 34-65.

Flamtermesky, H. (2014). Mujer frontera, experiencia de investigación acción participativa feminista (IAPF). Athenea Digital. Revista de Pensamiento e Investigación Social, 14 (4), 389-400.

Giménez, C., y Valente Adarme, X. (2010). El enfoque de los derechos humanos en las políticas públicas: ideas para un debate en ciernes. Cuadernos del Cendes, 27 (745), 1-80.

Global Rights. (2005). Guía anotada del protocolo completo de la ONU contra la trata de personas. Global Rights. Recuperada de: http://www.acnur.org/ fileadmin/scripts/doc.php?file=fileadmin/ Documentos/Publicaciones/2006/3556

Guendel, L. (2002). Políticas públicas y derechos humanos. Revista de Ciencias Sociales, 3 (97), 105-125.

Institut de Drets Humans. (2014). Derechos humanos y desarrollo. Barcelona: Institut de Drets Humans de Catalunya. Recuperado de: http:// www.idhc.org/arxius/recerca/DHE_ 08.pdf

Jiménez, W. G. (2007). El enfoque de los derechos humanos y las políticas públicas. Civilizar. Ciencias Sociales y Humanas, 7 (12), 31-46.

Jones, C. O. (1970). An introduction to the Study of Public Policy. 3a. edición. Belmont, Estados Unidos: Wadsworth Publishing Co.

Londoño Toro, B., Varón Mejía, A., y Luna de Aliaga, B. E. (2012). El delito de trata de personas: hacia la aplicación de estándares internacionales para la prevención, judicialización, protección y asistencia integral a las víctimas en Colombia. Revista de Derecho, (37), 198-230.

Mateus, A., Varón Mejía, A., Londoño Toro, B., Luna de Aliaga, B., y Vanegas Moyano, M. (2009). Aspectos jurídicos del delito de trata de 
personas en Colombia. Convenio interinstitucional entre la Oficina de las Naciones Unidas contra la Droga y el Delito en Colombia y Universidad Colegio Mayor de Nuestra Señora del Rosario. Recuperado de https:// www.unodc.org/documents/colombia/2013/ septiembre/Investigacion_U Rosario.pdf

Montenegro, V. (2015). Análisis de las fallas de implementación de la política pública de lucha contra la trata de personas en Colombia a partir de los instrumentos de política (Tesis de maestría) Facultad Latinoamericana de Ciencias Sociales, Quito, Ecuador.

Oacnudh. (2010). Principios y directrices recomendados sobre derechos humanos y trata de personas. Nueva York y Ginebra: Naciones Unidas.

Oficina de las Naciones Unidas Contra la Droga y el Delito. (2000). Protocolo para prevenir, reprimir y sancionar la trata de personas, especialmente mujeres y niños, que complementa la Convención de las Naciones Unidas contra la Delincuencia Organizada Transnacional. Palermo, Italia: Editorial Naciones Unidas.

Oficina de las Naciones Unidas contra la Droga y el Delito. (2010). Marco Internacional de Acción para la aplicación del Protocolo. Nueva York: Naciones Unidas.
Oficina del Alto Comisionado de las Naciones Unidas. (2006). Preguntas frecuentes sobre el enfoque de derechos humanos en la cooperación para el desarrollo. Recuperado de http://www.ohchr. org/Documents/Publications/FAQsp.pdf

Oficina del Alto Comisionado de Naciones Unidas. (2014). Los derechos humanos y la trata de personas. Nueva York y Ginebra: Oficina del Alto Comisionado de Naciones Unidas.

Organización Internacional para las Migraciones y Ministerio del Interior. (2012). Manual para la formulación de políticas públicas de lucha contra la trata de personas y el diseño y ejecución de planes de acción departamentales, distritales y/o municipales. Bogotá, Colombia: Ministerio del Interior y Organización Internacional para las Migraciones.

Roth, A. (2010). Enfoques para el análisis de políticas públicas. Bogotá, Colombia: Universidad Nacional.

Urrego Ortiz, F., y Quinche Ramírez, M. F. (2008). Los decretos en el sistema normativo colombiano. Una política estatal de invención normativa. Vniversitas, (116), 53-83.

Vargas, V. A. (1999). Notas sobre el estado y las políticas públicas. Bogotá, Colombia: Almudena. 